\title{
A New Interpretation of Magnetic Field Variation Associated with the Matsushiro Earthquakes
}

\author{
Hitoshi Mizutani and Tsuneo Ishido \\ Geophysical Institute, University of Tokyo \\ Tokyo, Japan
}

(Received December 10, 1975)

\begin{abstract}
Local magnetic field variation observed during the Matsushiro earthquake swarm in central Honshu, Japan, is well correlated with the variation of spring-water outflow but not with that of the seismic activity. This indicates that the origin of the magnetic field variation is not the stress-induced piezomagnetic effect but may be the water-induced electrokinetic effect proposed by Mizutani et al. (1975). The electrokinetic effect combined with the observed amount of water discharge is found to give the correct magnitude and sign of the local magnetic field variation observed at the two stations in Matsushiro area.
\end{abstract}

\section{Introduction}

Local geomagnetic effects associated with earthquakes have been searched by various authors since the late 19 th century (see e.g. Rikitake, 1968). These effects were termed tectonomagnetism by NAGATA (1969) and have been interpreted to be due to the stress-induced piezo-magnetic effects in rocks. Recently Mizutani et al. (1975) proposed theoretically that electrokinetic effects induced by water-diffusion may cause a detectable geomagnetic effect associated with earthquakes. It is desirable to look into the field data from this new point of view and to examine which effect, piezomagnetic or electrokinetic, is responsible for the observed geomagnetic field change.

However we have had few reliable data of the geomagnetic field change associated with earthquakes until drift free magnetometers such as the proton magnetometers were introduced (RIKITAKE, 1968; JoHnston et al., 1973). One of the most reliable data on the local magnetic field change was the observations made during Matsushiro earthquake swarm, in Japan (RIKITAKe et al., 1966; YAMAZAKI and RIKITAKE, 1970). The Matsushiro earthquake swarm consisted of more than 700,000 recorded earthquakes during late 1965 to early 1967 (HAGIWARA and IwATA, 1968). A variety of geophysical, geological and geochemical studies were carried out for the Matsushiro swarm (e.g. KaSAHARA, 1970; 
Tsuneishi and Nakamura, 1970). Synthesizing the observed temporal variations of land deformation, gravity, seismic activity and water out-flow, NuR (1974) and KISSLINGER (1975) concluded that dilatancy and water diffusion did occur in the source region of Matsushiro. On the other hand, STUART and JoHnston (1975) asserted that the Matsushiro earthquake swarm was caused by magma intrusion into a crust containing pre-existing horizontal shear stress. Stuart and Johnston did not attach much significance to the water outflow data which was taken to be one of the most important data by NUR (1974) and KISSLINGER (1975) but, instead, they used the data of magnetic field change as an evidence favoring the intrusive origin of the Matsushiro earthquake swarm. Stuart and Johnston's explanation on the observed change of the geomagnetic field at Matsushiro is based on the piezo-magnetic effect caused by stress due to the magma intrusion. We believe this explanation is not satisfactory, because they had to assume an incredibly high stress of 945 bars and also could not give any reason for the phase lag between the seismic activity peak and the magnetic anomaly peak. The present paper provides an alternative interpretation on the geomagnetic field change associated with the Matsushiro earthquake swarm.

\section{Geomagnetic Data}

Figure 1 shows a map of Matsushiro area and the locations of some points relevant to the present discussions. Rikitake et al. (1966) measured the total geomagnetic intensity at Matsushiro station (point $\mathbf{M}$ in Fig. 1) and Hoshina station (point $\mathrm{H}$ in Fig. 1) by proton precession magnetometers: the total intensity values at points $\mathrm{M}$ and $\mathrm{H}$ are designated $F_{\mathrm{M}}$ and $F_{\mathrm{H}}$ respectively hereafter. In order to obtain local geomagnetic effect, the data at points $\mathrm{M}$ and $\mathrm{H}$ were referenced to that $\left(F_{\mathrm{K}}\right)$ at the Kanozan permanent observatory which is about $180 \mathrm{~km}$ south-east of Matsushiro and free from the seismic activity. In Fig. 2 are plotted the five-day mean values of the local magnetic field differences, that is $\Delta F_{\mathrm{M}}=F_{\mathrm{M}}-\alpha F_{\mathrm{K}}$ and $\Delta F_{\mathrm{H}}=F_{\mathrm{H}}-\alpha F_{\mathrm{K}}$, where $\alpha$ is a numerical constant of about 1 to take the possible change of local susceptibility at $\mathrm{M}, \mathrm{H}$, and $\mathrm{K}$ stations into account. According to Rikitake (1968), the standard deviation of the weighted difference on normal days is 2.2 gammas. Since we use the 5-day means, the standard deviation of the data in Fig. 2 is about 1 gamma: the variation of $\Delta F_{\mathrm{M}}$ and $\Delta F_{\mathrm{H}}$ exceeding 2 gammas is significantly anomalous on $95 \%$ level. As clearly shown in Fig. 2, the $\Delta F_{\mathrm{M}}$ increased anomalously in September and October, 1966 and it decreased fairly rapidly after that period. The variation of $\Delta F_{\mathrm{H}}$ is less obvious than that of $\Delta F_{\mathrm{M}}$ but indicates the negative anomaly which is opposite to the $\Delta F_{\mathrm{M}}$.

Figure 2 also shows the temporal variation of the seismic activity at Matsu- 


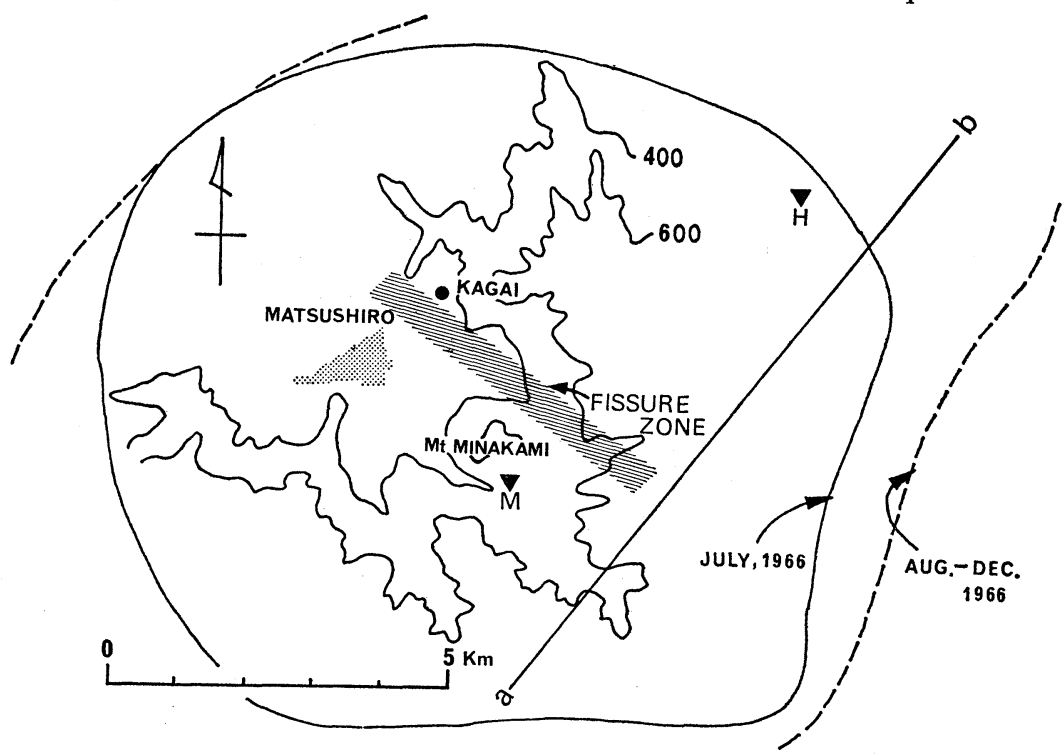

Fig. 1. Locations of the two magnetic stations (M, Matsushiro station, H, Hoshina station) and Kagai spring. The hatched zone indicates the fissure zone where a vast amount of water outflowed. Distribution of seismic activity is also shown for two periods (thin line curve, up to July, 1966; dotted line curve, from August to December, 1966).

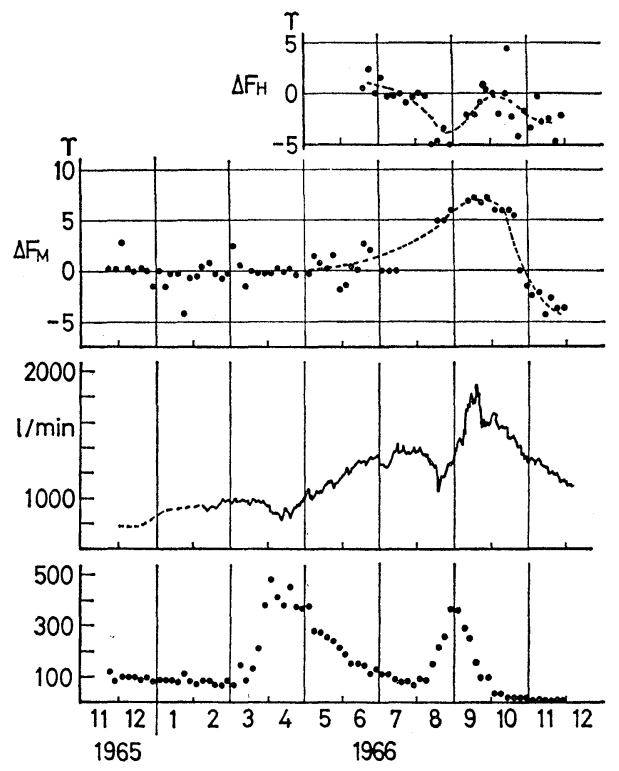

Fig. 2. Observed temporal variations of local magnetic anomaly at Hoshina station and at Matsushiro station, water outflow at Kagai spring, and seismicity. The magnetic data are five day means. Seismicity is represented by the number of felt earthquakes per five days. 
shiro during late 1965 to the end of 1966 . The two peaks of the seismic activity in Fig. 2 are the second and the third ones: the first one occurred during the October, 1965 to February, 1966 period. It is notable that the temporal variation of the local geomagnetic field does not correlate with the seismic activity. The peak of the geomagnetic anomaly is about one month behind the third peak of the seismic activity and no significant change of the geomagnetic intensity occurred during the second peak of the seismic activity. The apparent absence of correlation between the seismic activity and the magnetic variation indicates that the observed local magnetic variation is not a stress induced phenomenon which is proposed by STUART and Johnston (1975) or YAMAZAKI and Rikitake (1970). Moreover, too high a stress must be invoked to explain the observed magnitude of the magnetic anomaly if we interpret the anomaly by the piezomagnetic effect. Since earthquake mechanism studies (KASAHARA, 1970) show the stress drop accompanied with the earthquakes is only about 1 to $10 \mathrm{bars}$, the stress change of about 1000 bars assumed by STUART and JoHnston (1975) is unacceptably high. Therefore the piezomagnetic origin for the local magnetic variation at Matsushiro is not reasonable both qualitatively and quantitatively, whatever the origin of the stress is.

\section{Temporal Variation of Water Outflow}

A vast amount of ground water, which was rich in calcium, sodium and chlorine, outflowed throughout the zone of fissuring associated with fault (hatched area in Fig. 1) and its surrounding during September 1966 to April 1967. This phenomenon was also observed at existing springs and wells as an increase in discharge. Results obtained at one such spring (Kagai spring; a closed circle in Fig. 1) is shown in Fig. 2 (KASUgA, 1967; NogUCHI et al., 1969).

The temporal variation of the outflow at other springs and wells are not recorded so completely as that at Kagai spring, but all of those show a very similar pattern of variation to that shown in Fig. 2, as far as the period during which the data are available is concerned (IIJIMA, 1969).

STUART and Johnston (1975) suggested that the observed variation of the water discharge might be caused by precipitation and disregarded its tectonic implication. Geochemical studies of the water, however, indicate conclusively that the water is not surface one like rain but of deep origin (NoGUCHI et al., 1969).

As is clearly shown in Fig. 2, the temporal variation of the ground water discharge is very similar to that of the geomagnetic variation observed at Matsushiro station. The good correlation between the two suggests some causal interrelationship of the geomagnetic variation and ground water flow. Such a 
interrelationship of the geomagnetic variation and ground water flow was predicted by Mizutani et al. (1975) on the basis of electrokinetic phenomena. In the following we attempt to interpret the observed local geomagnetic field change in terms of the electrokinetic effect induced by the ground water diffusion.

\section{Electrokinetic Interpretation}

First we will construct a very simple model on the flow pattern of the ground water. As was described previously, the ground water outflowed mostly within the fissured zone and its surroundings. However, a substantial amount of the ground water seems also to have diffused horizontally in the underground from the fissured zone. This is inferred from the spatial expansion of the seismic activity with time (HAGIWARA and IWATA, 1968): we interpret the spatial expansion of the seismic activity during the period of July, 1966 to October, 1967 as a result of the water diffusion. As shown in Fig. 3, if we plot the characteristic dimension, $L$, of the hypocenter distribution as a function of time, $t$, we have the relation $L=\alpha \sqrt{ } \bar{t}$ which indicates a diffusion process. The above relation is also concordant with the relation of the precursor time versus the characteristic

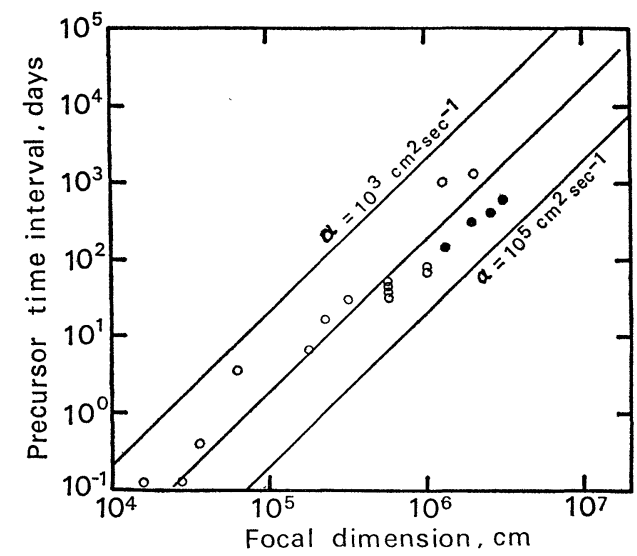

Fig. 3. Relation between characteristic dimensions of earthquakes and characteristic time intervals. The solid circles indicate expansion of seismically active region with time for the Matsushiro earthquake swarm during March, 1966 to October, 1967. The characteristic time interval is measured from March 1st, 1966 and the characteristic dimension is taken to be the length of the longer axis of ellipsoidal seismic zone (see also Fig. 4). The open circles show the observed relation of the precursor-time interval versus focal dimension. Three theoretical curves for spherical diffusion are also shown. 


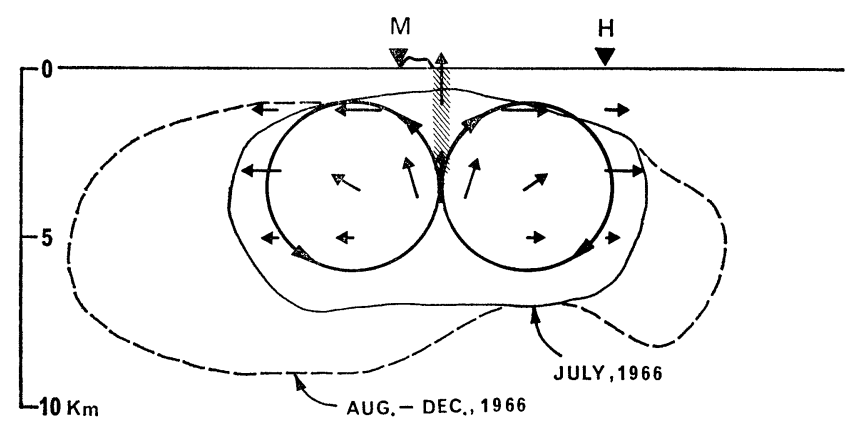

Fig. 4. Schematic diagram of water flow associated with the Matsushiro earthquake swarm. Two circles drawn by thick lines indicate the current pattern to be used for magnetic effect on the surface.

dimension of earthquakes obtained by Scholz et al. (1973) and ANDERson and Wнiтсомв (1975). From the proportional constant, $\alpha$, we estimate the bulk permeability, $k$, of this region to be $k=10^{7}$ nano-darcy, which agrees well with that estimated from the time-delay of the seismic activity accompanied with the water injection into a deep well drilled in the Matsushiro area (OHTAKe, 1974).

From the discussion above, it seems doubtless that the ground water moved horizontally as well as vertically. In Fig. 4, a schematic diagram of the water flow pattern along the line $a-b$ in Fig. 1 is shown. The arrows indicate the directions of the water flow. The hatched zone represents the faulted zone estimated by Kasahara (1970). Although the hypocenter distribution (thin line and dotted line in Fig. 4) suggests that the flow in the north-east direction is a little weaker than that in the south-west direction, we assume here that the ground water flowed symmetrically in bilateral directions from the fault. Since the seismically active region is $10 \mathrm{~km}$ wide and $5 \mathrm{~km}$ deep (HAGIWARA and IWATA, 1968), the area where the ground water diffused is also taken as $10 \mathrm{~km} \times 5 \mathrm{~km}$. This is a little larger than that the fault area of $7 \mathrm{~km} \times 3 \mathrm{~km}$ estimated by $\mathrm{KA}_{\mathrm{A}}$ SAHARA (1970) from seismological and geodetical observations. Because the fault area is just the area where a dislocation occurred, it is not unreasonable that we have a larger area of water-diffusing region than the fault area.

The total amount of water discharged in the fissure zone is estimated by IIJIMA (1969), summarizing the data of several wells and springs; his estimate is $10^{7} \mathrm{~m}^{3}$ during the period of September, 1966 to April, 1967 and $3 \times 10^{6} \mathrm{~m}^{3}$ during the period of September, 1966 to October, 1966, which is the most active period of water discharge. As the area of the fissure zone is $5 \mathrm{~km} \times 1 \mathrm{~km}$, the water outflow density during September to October 1966 is $10^{-7} \mathrm{~m}^{3} /\left(\mathrm{m}^{2} \cdot \mathrm{sec}\right)$ on the average. Since the amount of the horizontal water fiow is difficult to 
know correctly, we tentatively assume here that the water flow density in horizontal direction is equal to that of vertical water flow, i.e. $|J|=10^{-7} \mathrm{~m}^{3} /\left(\mathrm{m}^{2} \cdot \mathrm{sec}\right)$. The above estimate of the water flow density corresponds to the amount of water diffusing under the pore pressure gradient of $10 \mathrm{bars} / \mathrm{km}$. The pore pressure gradient above is a likely value judging from the stress drop of the earthquakes. The total amount of the horizontal water flow during the most active two months is then $3 \times 10^{7} \mathrm{~m}^{3}$. Such a ground water flow induces the electric current by the electrokinetic effect and the current in turn causes the geomagnetic variation on the ground surface. According to Mizutani et al. (1975), the coupling of electric current, $I$, and water flow, $J$, is expressed by the following two equations;

$$
\begin{aligned}
& -I=\phi \sigma \operatorname{grad} E-\frac{\phi \varepsilon \zeta}{\eta} \operatorname{grad} P \\
& -J=\frac{-\phi \varepsilon \zeta}{\eta} \operatorname{grad} E+\frac{k}{\eta} \operatorname{grad} P
\end{aligned}
$$

where

$$
\begin{aligned}
& \phi: \text { porosity } \\
& \sigma: \text { electrical conductivity of water } \\
& \varepsilon: \text { dielectric constant of water } \\
& \eta: \text { viscosity of water } \\
& \zeta: \text { zeta (streaming) potential } \\
& k: \text { bulk permeability of a porous medium } \\
& E: \text { electric potential } \\
& P: \text { pore pressure. }
\end{aligned}
$$

If the electric potential is uniform in the field under the present consideration, the electric current induced by the ground water flow is

$$
I=-\frac{\phi \varepsilon \zeta}{k} J
$$

or

$$
I=\frac{\phi \varepsilon \zeta}{\eta} \operatorname{grad} P
$$

The above equation gives the maximum current, because the electric potential is generated to suppress the electric current induced by the water flow. Using the numerical values estimated by Mizutani et al. (1975) for $\phi, \varepsilon, \eta$, and $\zeta$ which are listed in Table 1 , we can estimate the current, $I$, induced by the ground water flow, $J$, with Eq. (3) or (4). We also use the permeability, $k$, estimated in the previous section and the estimated amount of fluid flow, $J$. Then we have the current flow density, I, from Eq. (3), 
Table 1. Physical constants used in the present study.

\begin{tabular}{ccc}
\hline & CGS & MSK \\
\hline$\eta$ & $10^{-3}$ poise & $10^{-4} \mathrm{~N} \cdot \mathrm{sec} / \mathrm{m}^{2}$ \\
$\sigma$ & & $10^{-1} \mathrm{mho} / \mathrm{m}$ \\
$\varepsilon$ & 80 & $80 /\left(4 \pi \times 9 \times 10^{9}\right) \mathrm{F} / \mathrm{m}^{2}$ \\
$\zeta$ & & $-100 \mathrm{mV}$ \\
$k$ & $10^{-10} \mathrm{~cm}^{2}$ & $10^{-14} \mathrm{~m}^{2}$ \\
$\phi$ & $10^{-2}$ & $10^{-2}$ \\
\hline
\end{tabular}

$$
|I|=8 \times 10^{-6} \mathrm{~A} / \mathrm{m}^{2} \text {. }
$$

The total current induced by the water flow is therefore

$$
|I|_{\text {total }}=4 \times 10^{2} \mathrm{~A} \text {. }
$$

From the magnitude of the electric current and the current flow pattern which is assumed to be the same as that of water flow shown in Fig. 4, the magnetic field induced by the elctric current is calculated with Biot-Savart's law. Because we have only to know orders of magnitude of the magnetic field, we approximated the electric current pattern as two cylinders in contact with each other at the fissured zone, as shown in Fig. 4. Assuming that the current flows on the surface of the cylinder of $2.5 \mathrm{~km}$ in radius and $5 \mathrm{~km}$ in length with its center at $3.5 \mathrm{~km}$ depth, the induced magnetic field intensities become

and

$$
\left.\begin{array}{rl}
H_{\text {eastward }} & =-6 \text { gammas } \\
H_{\text {northward }} & =5 \text { gammas } \\
H_{\text {vertical }} & =0
\end{array}\right\} \text { at Matsushiro station }
$$

$$
\left.\begin{array}{rl}
H_{\text {eastward }} & =5 \text { gammas } \\
H_{\text {northward }} & =-4 \text { gammas } \\
H_{\text {vertical }} & =0
\end{array}\right\} \text { at Hoshina station. }
$$

The magnetic fields calculated above cause the change of the total intensity of 4 gammas at Matsushiro station and -3 gammas at Hoshina station. These magnetic field changes are in very good agreement with the observed ones shown in Fig. 2. Although the results are slightly dependent on the assumed geometry of the electric current pattern, plausible current patterns give the same order of magnitude of the induced magnetic field. If we take the cylinder of $3 \mathrm{~km}$ in radius and put its center at depth of $5 \mathrm{~km}$, the total intensity changes at Matsushiro station and Hoshina station become 1.5 gammas and -2.5 gammas respectively. If we assume a plane sheet current of $10 \mathrm{~km}$ width and $5 \mathrm{~km}$ thickness, instead of the cylindrical ones, it also gives about 10 gammas change in the 
total intensity on the surface of the sheet. In short, the horizontal electric current of about $4 \times 10^{2} \mathrm{~A}$ in the upper $5 \mathrm{~km}$ layer is large enough to cause the variation of the local geomagnetic field observed at Matsushiro and Hoshina stations.

\section{Conclusions}

The temporal variation of the local magnetic intensity observed during the Matsushiro earthquake swarm appears to be explained well by the electrokinetic phenomena induced by water diffusion. In contrast to STUART and Johnston's (1975) conclusion, the local magnetic field anomaly also supports the hypothesis that dilatancy and fluid flow took place in the Matsushiro area as suggested by NUR (1974) and KissLINGER (1975). If fluid diffusion takes place preceding or following earthquakes, the electrokinetic effect induced by the fluid diffusion may give rise to a geomagnetic or geoelectric phenomenon associated with earthquakes. The diffusion-type variation of the local geomagnetic variation observed at Nankaido earthquake $(M=8.1$ ), Japan, in 1946 (KAto and Utashiro, 1949; Nagata, 1972) might also be due to the electrokinetic effect.

Finally we should make the following observation: the present analysis is based on the assumption of the stationary electrokinetic phenomena in an isotropic medium. Real phenomena in nature, however, are not stationary but probably highly transient and anisotropic. Therefore a more detailed analysis is necessary to compare the theoretical result with observations quantitatively, although we believe the present analysis gives the results of the first order approximation.

We thank Professor H. Takeuchi for his constant encouragement. We also wish to acknowledge Dr. S. Ohnishi and Messrs. S. Karato and T. Yokokura for their valuable comments.

\section{REFERENCES}

Anderson, D.L. and J.H. Whitcomb, Time dependent seismology, J. Geophys. Res., 80, 1497$1503,1975$.

Hagiwara, T. and T. Iwata, Summary of the seismographic observation of Matsushiro swarm earthquakes, Bull. Earthq. Res. Inst., 46, 485-515, 1968.

Irjima, H., Surface geology of Matsushiro area and disasters by the Matsushiro swarm, in Studies on the Matsushiro Earthquake Swarm, pp. 103-115, National Research Center for Disaster Prevention, Tokyo, 1969 (in Japanese).

Johnston, M.J.S., R.E. SMith, J.R. Johnstons, and F.J. Williams, A search for tectonomagnetic effects in California and western Nevada, in Proc. Conf. Tectonic Problems of the San Andreas Fault System, edited by R.L. Kovach and A. Nur, pp. 225-237, Geological Sciences, Vol. 13, Stanford Univ., 1973.

Kasahara, K., The source region of the Matsushiro swarm earthquakes, Bull. Earthq. Res. Inst., 48, 581-602, 1970. 
KASUgA, I., Aspect on the relation of thermal water and Matsushiro earthquakes in Kagai hotspring area, Nagano prefecture, J. Geogr., 76, 16-26, 1967 (in Japanese).

KATO, Y. and S. UTASHIRo, On the changes of the terrestrial magnetic field accompanying the great Nankaido earthquake of 1946, Sci. Rep. Tohoku Univ., Sth Ser., 1, 40-41, 1949.

Kisslinger, C., Processes during the Matsushiro, Japan, earthquake swarm as revealed by leveling, gravity, and spring-flow observations, Geology, 3, 57-62, 1975.

Mizutani, H., T. Ishido, T. YoKokURA, and S. OHNishi, Electrokinetic phenomena associated with earthquakes, Geophys. Res. Lett., 1976 (to be submitted).

Nagata, T., Tectonomagnetism, Int. Assoc. Geomag. Aeron. Bull., 27, 12-43, 1969.

NaGATA, T., Application of tectonomagnetism to earthquake phenomena, Tectonophysics, 14, 263-271, 1972.

Noguchi, K., S. Ueno, and T. Nishido, Geochemical study on the variation of hot spring waters caused by the Matsushiro earthquake swarm, Onsen Kagaku (J. Hotspring), 20, 6793, 1969 (in Japanese).

Nur, A., Matsushiro, Japan, earthquake swarm: Confirmation of the dilatancy-fluid diffusion model, Geology, 2, 217-221, 1974.

Онтаке, M., Seismic activity induced by water injection at Matsushiro, Japan, J. Phys. Earth, 22, 163-176, 1974.

Rikitake, T., Geomagnetism and earthquake prediction, Tectonophysics, 6, 59-68, 1968.

Rikitake, T., Y. Yamazaki, Y. Hagiwara, K. Kawada, M. Sawada, Y. Sasai, T. Watanabe, K. Momose, T. Yoshino, K. Otani, K. Ozawa, and K. Sanzai, Geomagnetic and geoelectric studies of the Matsushiro earthquake swarm (1), Bull. Earthq. Res. Inst., 44, 363408, 1966; (3), see also ibid., 44, 1335-1370, 1966.

Scholz, C.H., L.R. Sykes, and Y.P. AgGarwal, Earthquake prediction: A physical basis, Science, 181, 803-810, 1973.

Stuart, W.D. and M.J.S. Johnston, Intrusive origin of the Matsushiro swarm, Geology, 3, 6367, 1975.

Tsuneishi, Y. and K. NAKamUra, Faulting associated with the Matsushiro swarm earthquakes, Bull. Earthq. Res. Inst., 48, 29-51, 1970.

YAMAZAKI, Y. and T. RiKitAKE, Local anomalous change in the geomagnetic field at Matsushiro, Bull. Earthq. Res. Inst., 48, 637-643, 1970. 